\title{
Practical Studio Practices of Study Illustrations: The Art+Graphic Hybrid Style of Architecture
}

\author{
Maria Mohammad ${ }^{1}$, Nor Azillawati Zamri ${ }^{2}$, Halida Harun ${ }^{3}$ \\ \{mariafaisal2001m@gmail.com ${ }^{1}$, pu3ila82@gmail.com², halida@kkktu.edu.my ${ }^{3}$ \} \\ Politeknik Merlimau, Melaka, Malaysia ${ }^{13}$ \\ Kolej Komuniti Kuala Terengganu,Malaysia ${ }^{2}$
}

\begin{abstract}
This research aims to suggest systematic measures in helping the difficulty of design students who do not have the wisdom to visualize the object of study drawing in a three-dimensional (3D) illustration manually. Study drawings that have 'stroke' lines 'hybrid style' Art' and 'Architecture Graphic Presentation Drawing' (A + AGPD) systematic approach of visualization and proportionality as well as interesting that can be learned without the wisdom of drawing explored. Qualitative approach research using phenomenological design through interviews with Subject Matter Expert (SME), visual recording, observation applied as methodology in analyzing the study findings. Data were analyzed using thematic analysis of FOUR (4) Subject matter Expert (SME) informants based on Feldman's Art Criticism theory. Visual Art Line Techniques (LVA), Quality Lines (3Dvgk), Cool Hot Color Concept, Color Intensity Concept and Stroke Line style (gSLine) themes identified. Synthesis of the identified themes there are SEVEN (7) steps of the 'A + AGPD' Study Drawing Hybrid Model introduced. This study helps to improve the visualization skills of students who do not have the natural wisdom to draw in order to be able to draw study drawings according to the practice of this practical studio.
\end{abstract}

Keywords: Study Illustrations, Line Visual Art (LVA), Quality Lines (3Dvgk), Stroke Line style (gSLine)

\author{
Amalan Studio Praktis Ilustrasi Lukisan Kajian: \\ Gaya Hibrid Seni + Grafik Seni Bina
}

\begin{abstract}
Abstrak. Penyelidikan ini bertujuan mencadangkan langkah sistematik dalam membantu kesukaran mahasiswa bidang reka yang tiada kearifan memvisualisasi objek lukisan kajian secara ilustrasi tiga dimensi (3D) secara manual. Lukisan kajian yang mempunyai garisan 'stroke' gaya hibrid 'Art' dan 'Architecture Graphic Presentation Drawing' (A + AGPD) pendekatan sistematik visualisasi dan proporsionaliti serta menarik yang boleh dipelajari tanpa kearifan melukis diteroka. Penyelidikan pendekatan kualitatif yang menggunakan rekabentuk fenemologi melalui wawancara bersama Subject Matter Expert (SME), rekaman visual, pemerhatian diaplikasi sebagai metodologi dalam menganalisis dapatan kajian. Data dianalisis menggunakan analisa tematik terhadap informan EMPAT (4) orang Subject matter Expert (SME) berdasarkan teori Kritikan Seni Feldman. Teknik Line Visual Art (LVA), Garisan Kualiti (3Dvgk), Konsep Warna Panas Sejuk, Konsep Intensiti warna dan gaya Stroke Line (gSLine) tema yang dikenalpasti. Sintesis daripada tema yang dikenalpasti terdapat TUJUH (7) langkah Model Hibrid Lukisan Kajian 'A+AGPD' diperkenalkan. Kajian ini membantu peningkatan kemahiran visualisasi
\end{abstract}


mahasiswa tidak mempunyai kearifan semula jadi melukis agar dapat melukis lukisan kajian mengikut amalan studio praktis ini.

Kata kunci: Lukisan Kajian, Line Visual Art (LVA), Garisan Kualiti (3Dvgk), gaya Stroke Line(gSLine)

\section{Pendahuluan}

Penerokaan medium dan kreativiti artis yang menggunakan pelbagai medium bukanlah teknologi semata-mata diteroka. Ini kerana pelbagai medium yang telah diproses dan digabungkan sepenuhnya dikendalikan dalam menghasilkan karya seni yang lebih kontemporari [1], [2]. Kajian Mayo tahun 2012, disokong oleh kajian Guo, Cao, Xie, Jin, \& Wang pada tahun 2017 bahawa lukisan pengkaryaan tidak pentingkan perkadaran sehingga mengganggu literasi visual pengunjung[4].

Berdasarkan pengalaman penyelidik selama 10 hingga 20 tahun mengajar bidang seni reka, isu visualisasi dalam kalangan mahasiswa, mereka kurang mahir dalam mengilustrasikan objek 3 Dimensi (3D) secara lukisan bebas. Gaya melukis semasa tahun-tahun persekolahan masih diaplikasikan dalam peringkat kuliah pengajian tinggi [5]. Isu mahasiswa berkemahiran rendah menvisualisasi lukisan kajian bukan isu baru dalam sistem pendidikan di Malaysia, Indonesia juga seluruh dunia [6]

Isu ini menjadi fenomena berdasarkan kajian liteatur yang dilakukan 1982 sehingga 2013. Kajian Nordin dan Saud tahun 2006 dan Razak 2010 membincangkan penghasilan karya yang mempunyai aspek estetik dan emosi antara nilai tambah yang boleh diterapkan [8] dalam proses penghasilan lukisan kajian. Lukisan Kajian yang tepat akan menghasilkan idea, emosi dan subjek sebenar dalam amalan kerja praktis sudio [9].

Penyelidikan ini membantu mahasiswa tidak mempunyai kearifan semulajadi memvisualisasikan visual spatial ilustrasi 3 dimensi yang boleh diaplikasikan. Objektif penyelidikan ini untuk mensintesis pendekatan sistematik baru dalam lukisan kajian dengan simbiosis baru dalam disiplin seni dan seni bina secara sistematik melalui proporsionaliti serta menarik yang boleh dipelajari.

\section{Literatur}

Lukisan kajian adalah teknik menurut Brooks tahun 2003 dan membuat bentuk objek dengan struktur bentuk, garis garis, dakwat, pen, pensil, krayon, arang dan kapur adalah media utama dalam visualisasi ilustrasi lukisan kajian[10]. Teknik melukis dengan penerokaan sederhana dengan gabungan mana-mana cat, media kering dan basah untuk menghasilkan objek ilustrasi 3 dimensi secara manual akan menghasilkan karya kreativiti [11], [12]

Hibridisasi adalah proses menggabungkan dua atau lebih medium yang digabungkan menjadi satu karya seni. Menurut Elun Loros, (2006) menjelaskan bahawa hibridisasi adalah sesuatu teknik atau bersilang[13]. Dalam konteks seni, ia adalah medium yang mempunyai ciri atau sifat yang tidak sama dengan gabungan atau penggabungan untuk menghasilkan karya seni. Amalan studio menjalani proses hibridisasi di mana para seniman akan memilih medium yang sesuai dan kemudian menggabungkan medium itu menjadi karya seni dengan 
menggunakan setiap teknik. Mahasiswa mengabaikan aspek penggunaan proporsionaliti [2], [14]. Penemuan ini disokong oleh kajian lukisan yang tidak berkaitan dengan penggunaan proporsi yang mengganggu pemerhati literasi visual[3].

Lukisan teknik imej yang digambarkan atas permukaan yang rata. Lukisan garisan, dakwat, pen, pensil, krayon, arang dan kapur sebagai media utama. Dalam penghasilan lukisan boleh dibuat dengan mana-mana kombinasi cat, media kering dan media basah [15], [16]. Lukisan mengandungi jiwa dan rohani nilai-nilai yang akan membolehkan pengeluaran karya seni yang boleh dihargai. Karya seni terbahagi dua iaitu ilustrasi dan karya seni sebenar[17]. Ilustrasi seni melibatkan lukisan, catan, fotografi, seni cetak, reka bentuk grafik dan lainlain.Karya seni sebenar termasuk bentuk arca, seni bina, pekerjaan logam, reka bentuk kaca, seramik, kerja serat, reka bentuk produk dan lain-lain[18].

Imej visualisasi lukisan kajian wujud dalam 2D, tetapi mempunyai garisan,isipadu, tinggi dan lebar, warna yang boleh menjana ilusi optik manusia. Ilustrasi pada permukaan mungkin rata, tetapi boleh wujud literasi mata rupa bentuk objek dalam 2D dan 3D berdasarkan ilustrasi artis. Permukaan rata adalah di mana artis melaksanakan imej mereka.Permukaan rata juga boleh mewakili satah rujukan khayalan di mana artis boleh membuat ilusi ruang [19]

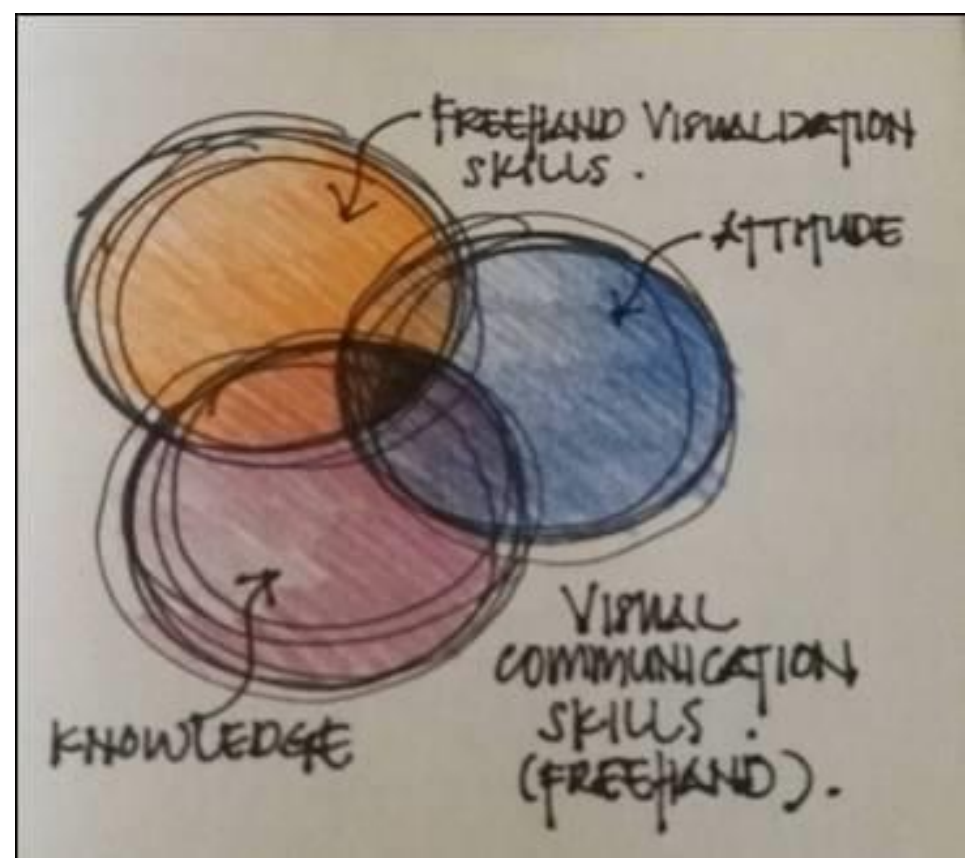

Gambar 1. Adabtasi ilustrasi Informan luar dalam isu kajian AGPD proses mendalami fenomena visualisasi Lukisan Kajian (AGPD). Pendekatan amalan studio praktis gaya hibrid Art dalam model 'A+AGPD' menurut pandangan dan cadangan informan. Ilustrasi oleh Drawzania

Gambar 1 adalah cadangan dan pandangan informan luar tentang amalan studio praktis gaya hibrid Art dalam model 'A+AGPD'. Informan membincangkan isu visualisasi ini dan isu ini menjadi fenomena berdasarkan kajian liteatur yang dilakukan 1982 sehingga 2019 di Malaysia Indonesia mahupun dunia seni global[1], [20]. Manakala penghasilan karya Lukisan Kajian disiplin ilmu perekaan khususnya seni bina aspek estetik dan emosi anatara nilai tambah yang boleh diterapkan dalam proses penghasilan Lukisan Kajian. Lukisan Kajian yang 
tepat akan menghasilkan karya yang idel beremosi dan subjek sebenar dalam amalan kerja praktis sudio. Siswazah pra-diploma seni menghasilkan karya lebih bersifat artistik. Ini menyebabkan hasil karya yang kurang berkadaran dan kelihatan cacat atau kadang-kadang kelihatan berlebih-lebihan bermain dengan emosi penonton [3]. Lukisan pengkaryaan tidak pentingkan perkadaran sehingga mengganggu literasi visual pengunjung[21].

\section{Metode}

Organisasi Seni Visual Line (LVA) dianalisis berdasarkan elemen seni: penampilan, garis, bentuk, bentuk, tekstur dan warna untuk membentuk tiga dimensi ilustrasi garisan secara manual (3DiGm) dalam kalangan Subject Matter Expert (SME). Perbezaan dan variasi kerana dimensi sintagmatik dan amalan studio dianalisis menggunakan teori kritikan Feldman. Gaya garisan stroke line (gSLine) ilustrasi setiap SME berbeza-beza dengan mengaplikasikan empat jenis garisan berkualiti. Penyelidikan kualitatif ini menggunakan rakaman visual, wawancara pemerhatian dan analisis karya sebagai metodologi.

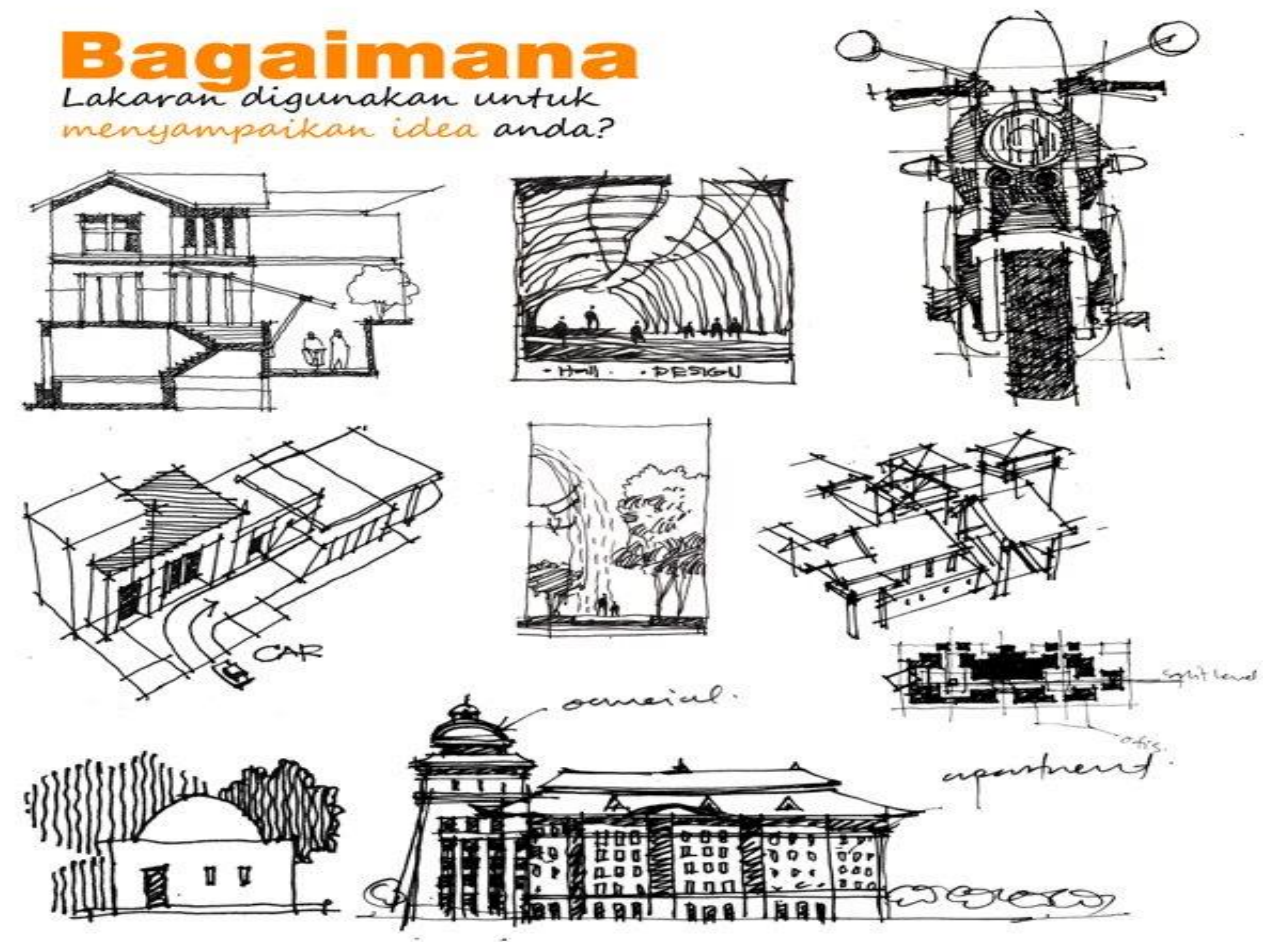

Gambar 2. Analisis Karya Lukisan Kajian SME bagi mengenalpasti gaya lukisan kajian yang pendekatan sistematik visualisasi dan proporsionaliti serta menarik yang boleh dipelajari tanpa kearifan melukis diteroka. Ilustrasi oleh AJ Reka 


\section{Hasil dan Pembahasan}

Pendekatan sistematik baru dalam sintesis proses latihan studio oleh informan Subject Matter Expert (SME) dalam 'Art' dan 'Architecture Graphic Presentation Drawing' (A + AGPD). Penyelidikan kualitatif ini menggunakan rakaman visual, wawancara, pemerhatian dan peniruan digunakan sebagai metodologi dalam proses visualisasi. Teori kritikal digunakan untuk menganalisis karya SME. Organisasi Line Visual Art (LVA) menggunakan teknik kotak dan dianalisis berdasarkan elemen seni: rupa, garis, bentuk, bentuk, tekstur dan warna untuk membentuk tiga gambar dimensi dianalisis. Analilis tematik menggunakan teori kritikal Edmund Burke Feldman dalam kajian ini.

Tabel 1. Jadual analisis Gaya Lukisan Kajian SME menggunakan Teori Kritikan Feldman

\begin{tabular}{|c|c|c|}
\hline Bil. & Peringkat Analisis & Penjelasan \\
\hline \multirow[t]{6}{*}{1.} & Deskripsi & - Lukisan Kajian Gaya Hibrid Seni+Seni Bina \\
\hline & & - Lukisan Kajian ; \\
\hline & Pengkaji menganalilis & i. Pendekatan sistematik \\
\hline & $\begin{array}{l}\text { karya DUA (2) SME seni } \\
\text { dan DUA (2) SME seni }\end{array}$ & ii. Proporsionaliti \\
\hline & bina mahir lukisan kajian. & iii. Menarik \\
\hline & & - tanpa kearifan melukis tetap boleh melukis \\
\hline \multirow[t]{3}{*}{2.} & Analisis & \\
\hline & Analisis $\quad$ terperinci & - $\quad$ Rujuk jadual 2 \\
\hline & $\begin{array}{l}\text { Lukisan Kajian gaya 'A+ } \\
\text { AGPD' }\end{array}$ & \\
\hline \multirow[t]{6}{*}{3.} & Lukisan Kajian 'Gaya & $\begin{array}{l}\text { - Teknik menghasilkan Lukisan Kajian 'lukisan } \\
\text { bebas tangan 'gaya seni bina dan seni halus ini } \\
\text { dinilai. Isu kelainan gaya Lukisan Kajian SME seni } \\
\text { bina dan seni halus dianalisis pakar rujuk. }\end{array}$ \\
\hline & Bebas Tangan' & $\begin{array}{l}\text { - Bagaimanakah pandangan informan luar mengenai } \\
\text { isu hibrid dan inter-disiplin dalam seni? }\end{array}$ \\
\hline & $\begin{array}{l}\text { - Media Felt Tip Pen } \\
+3 \text { size }\end{array}$ & divisulka \\
\hline & i. Mata Halus & praktis: \\
\hline & ii. Mata sederhana & - $\quad$ Ilmu Line Visual Art (LVA) \\
\hline & iii. Mata Besar & - $\quad$ Ilmu Garisan Kualiti (3Dvgk) \\
\hline
\end{tabular}




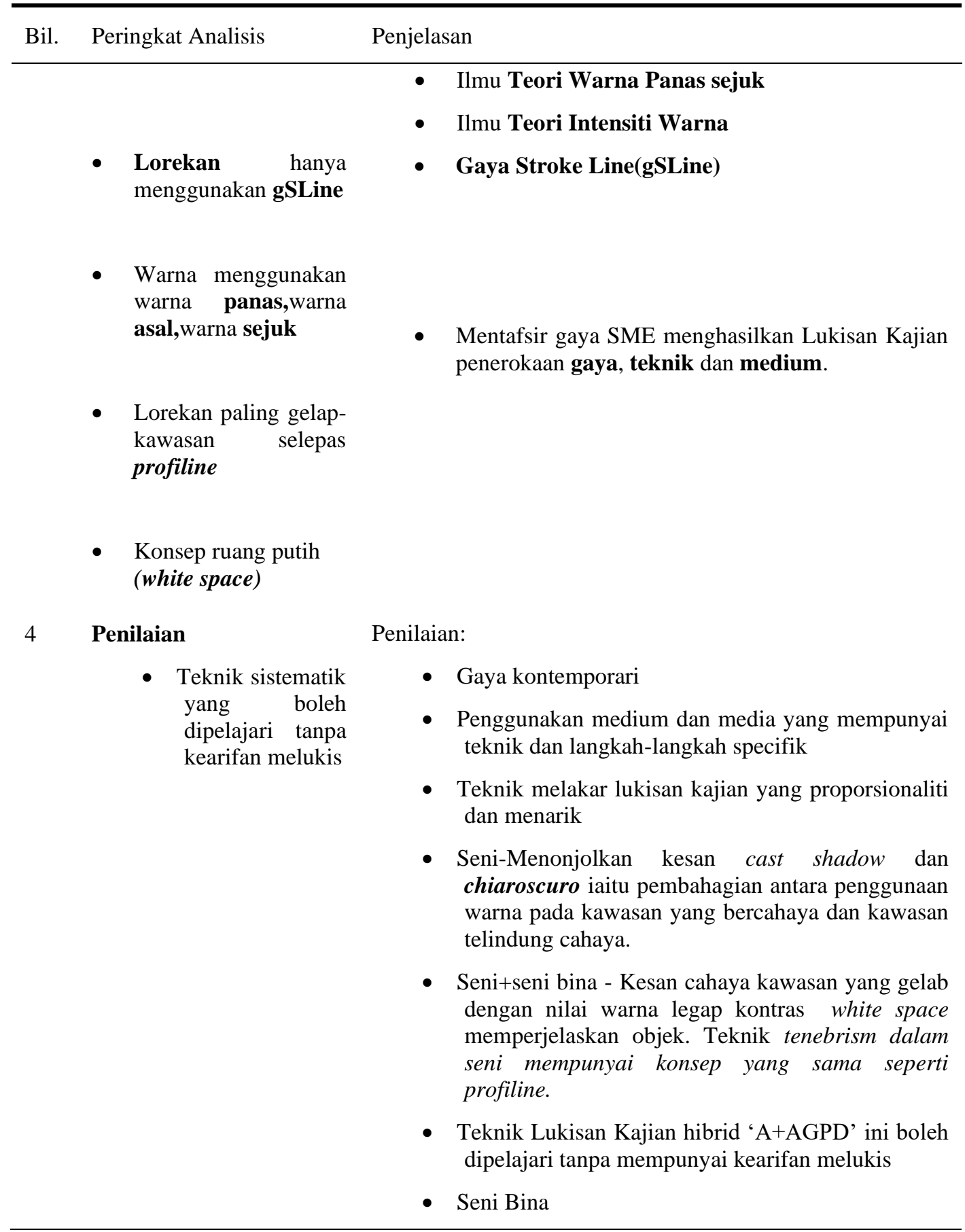


Tabel 2. Tabel analisis Gaya Lukisan Kajian SME menggunakan Teori Kritikan Feldman

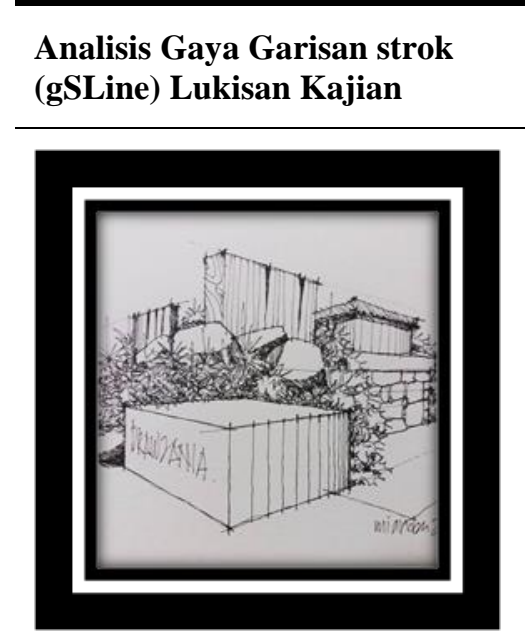

Media

Ilmu

Penjelasan

Hisan Kajian

\section{Medium \\ Medium Feltip \\ Pen}

Artline 0.6


\section{Ilmu Line Visual Art (LVA)}

i. Garis Bina (Struktur Berkotak isometrik/ oblik)
ii. Garis Objek
iii. Garis Profiline (Garisan tebal 3Dvgk)
i. Mata 0.2 (mata halus)
ii. Mata 0.5 (mata sedang)
iii. Mata 0.6 artline (mata besar)

\section{Ilmu Garisan Kualiti (3Dvgk)}
i. Berterusan
ii. Seimbang
iii. Bersilang
iv. Profiline

Ilmu Teori warna

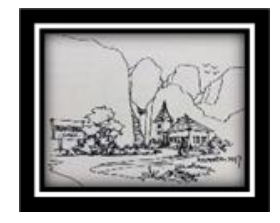
i. Warna Panas
ii. Warna Asal
iii. Warna Sejuk

Ilmu Teori Intensiti Warna

i. Warna Monokromatik

ii. Warna Kromatik

iii. Warna Akromatik

\section{Gaya Stroke Line(gSLine)}

i. Bayang
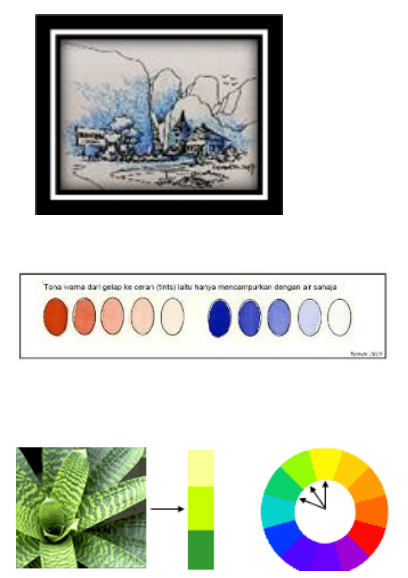

i. Garisan Profiline 


\begin{tabular}{|c|c|c|}
\hline \multirow{4}{*}{$\begin{array}{l}\text { Analisis Gaya Garisan strok } \\
\text { (gSLine) Lukisan Kajian }\end{array}$} & Media & Penjelasan \\
\hline & $\begin{array}{l}\text { Teknik } \\
\text { Lorekan }\end{array}$ & \\
\hline & Artline 0.6 & \\
\hline & & $\begin{array}{l}\text { Lorekan gurisan } \\
\text { mata pen sebanyak } \\
45 \text { darjah }\end{array}$ \\
\hline & $\begin{array}{l}\text { Visualisasi } \\
\text { Objek 3D }\end{array}$ & \\
\hline & & $\begin{array}{l}\text { Garisan tebal tepi } \\
\text { objek bagi } \\
\text { menjelaskan objek }\end{array}$ \\
\hline en & $\begin{array}{l}\text { Medium pensil } \\
\text { warna dan cat } \\
\text { air } \\
\text { *kesan cast } \\
\text { shadow dan } \\
\text { chiaroscuro } \\
\text { iaitu } \\
\text { pembahagian } \\
\text { antara } \\
\text { penggunaan } \\
\text { warna pada } \\
\text { kawasan yang } \\
\text { bercahaya dan } \\
\text { kawasan } \\
\text { telindung cahaya }\end{array}$ & $\begin{array}{l}\text { Kesan lebih emosi } \\
\text { dan kesan realistik }\end{array}$ \\
\hline
\end{tabular}




\begin{tabular}{lllll}
\hline $\begin{array}{l}\text { Analisis Gaya Garisan strok } \\
\text { (gSLine) Lukisan Kajian }\end{array}$ & Media & Ilmu & Penjelasan \\
\hline & $\begin{array}{l}\text { *Teknik } \\
\text { tenebrism } \\
\text { kawasan yang } \\
\text { gelab dengan } \\
\text { nilai warna } \\
\text { kontras } \\
\text { memperjelaskan } \\
\text { objek. }\end{array}$ \\
\hline
\end{tabular}

\section{Persamaan, rumus dan kode}

Organisasi Seni Visual Line (LVA) dianalisis berdasarkan elemen seni: penampilan, garis, bentuk, bentuk, tekstur dan warna untuk membentuk objek lukisan garis ilustrasi tiga dimensi secara manual. Perbezaan dan variasi kerana dimensi sintagmatik dan mekanikal pada amnya mustahil untuk dikesan dalam produk akhir (lakaran akhir). Gaya melukis berbezabeza dari orang ke orang, tetapi orang yang sama juga boleh menggunakan gaya alternatif yang berbeza dengan struktur lukisan dan media. Konsistensi dalam gaya dan teknik menggambar bukanlah keutamaan untuk membuat lakaran denah lantai pada peringkat reka bentuk awal.

Struktur kotak adalah dengan menggunakan pendekatan isometrik, oblik dan perspektif adalah teknik khusus yang diaplikasikan bagi menghasilkan Lukisan Kajian yang berkadaran dari kesan visual. Identiti menjelaskan gSLINE Lukisan Kajian seni bina ditambah dengan kesan white space. Ilusi yang divisualkan bersahaja, gSLineyang berterusan, sampaian terus, berkadaran, ceria dan bervestail dan emosi.

Intensiti warna adalah pengetahuan asas teori dan pengetahuan telah belajar mendapatkan karya seni yang cemerlang. Intensiti merujuk kepada kemurnian rona [14]. Intensiti juga dikenali sebagai kroma atau ketepuan. Intensiti atau kesucian rona tertinggi adalah spektrum warna kesan karya seni.

Sintesis pengkaji berdasarkan kajian literatur dan kajian lapangan terhadap SME pendekatan tenebrisme satu lagi ciri penting gaya seni pengkaryaan yang boleh dicadangkan dalam model hibrid 'A+AGPD'. Tenebrisme berasal dari perkataan tenebroso yang berasal dari Itali, yang bermaksud keruh. Tenebrisme mengandungi kawasan gelap yang besar, yang sangat kontras dengan kawasan cahaya yang lebih kecil. Gaya ini mewujudkan rasa drama yang lebih tinggi. Bayang-bayang yang sangat dalam bersaing dengan tempat cahaya dramatik melalui analisis pengkaji dapat melahirkan model 'A+AGPD' yang melahirkan daya visual, emosi dan estetik (dVEE) yang beremosi.

Gaya tenebris memenghasilkan kesan kontras dengan kesan cahaya dan gelap. Secara umum, semakin besar perbezaan antara cahaya dan gelap dalam imej, semakin besar kesan dramatik. Ini banyak digunakan oleh pembikin filem, artis video, dan jurugambar yang bekerja 
di hitam dan putih namun dalam kajian Lukisan Kajian yang mempunyai ciri-ciri dVEE gaya tenebrisme sesuai diaplikasi dalam amalan studio ini.

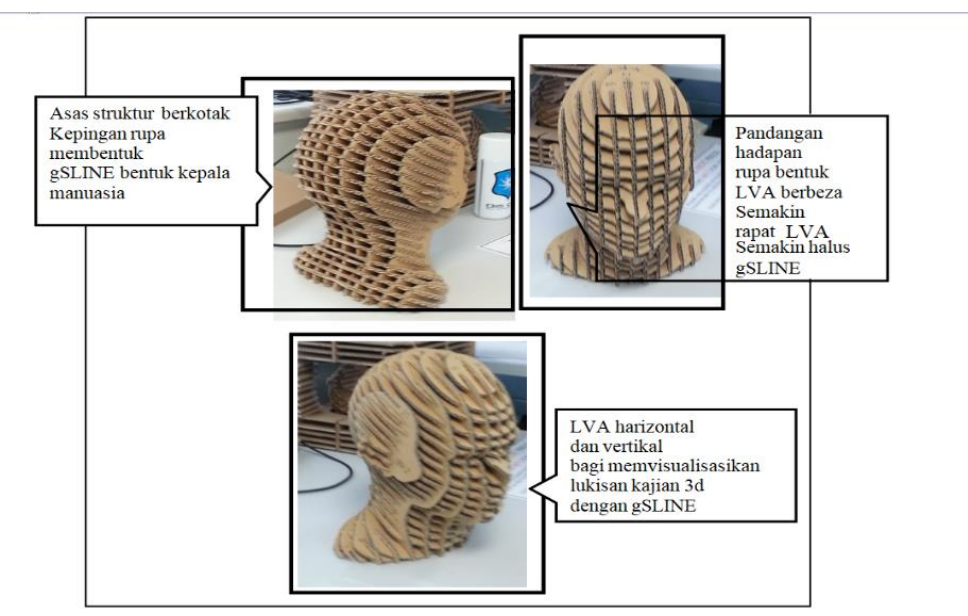

Gambar 3. Perpaduan simulasi. Bagaimana LVA terhasil melalui rupa terbentuk gSLINE dalam memvisualkan Lukisan Kajian

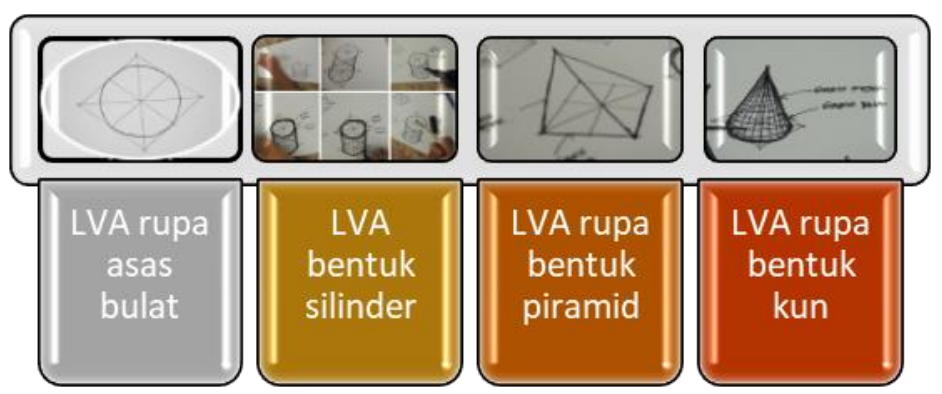

Gambar 4. Sintesis LVA dengan menggunakan teknik kotak berstruktur

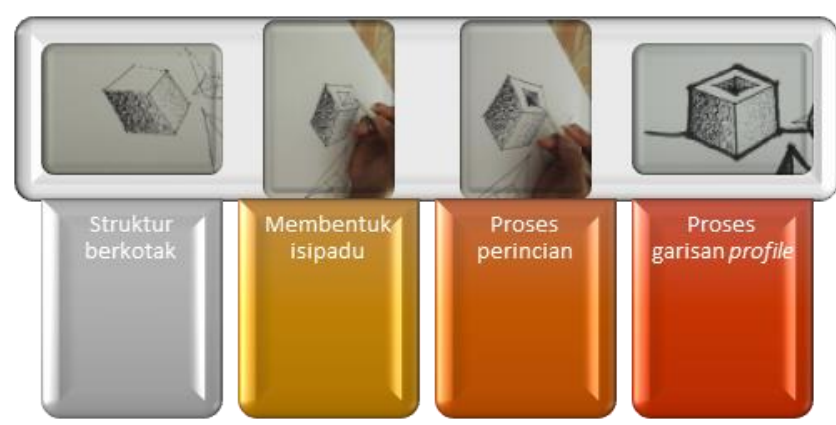

Gambar 5. Langkah-langkah bagi menghasilkan Lukisan Kajian dicadangkan menggunakan LVA 


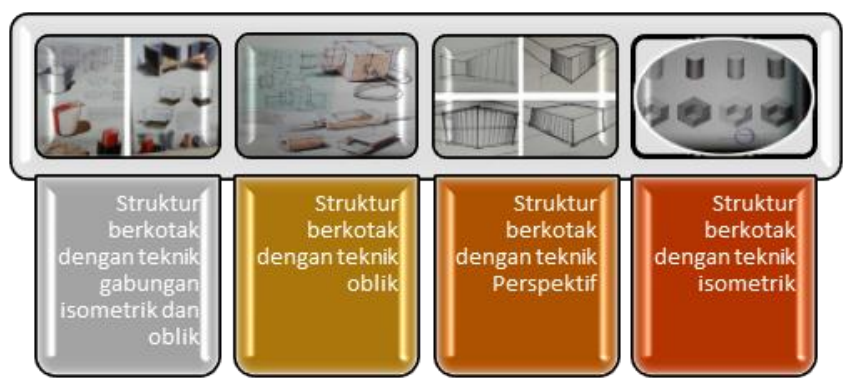

Gambar 6. Teknik struktur berkotak aplikasi pendekatan lukisan kejuruteraan (seni bina) melalui teknik perspektif, oblik dan isometrik

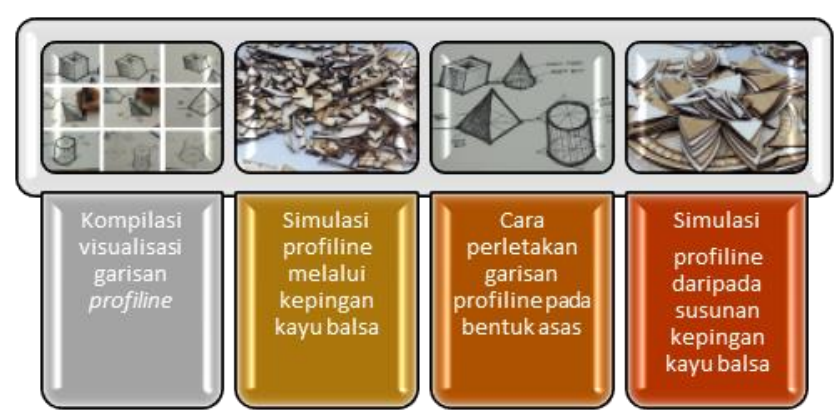

Gambar 7. Visualisasi dan simulasi garisan profil bagi menjelaskan jarak dan isipadu objek 3d

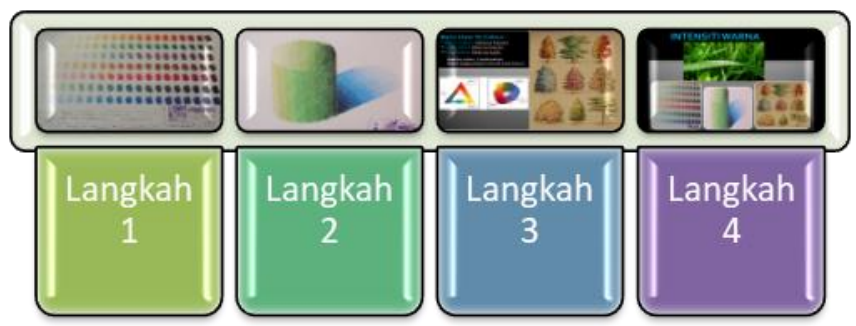

Gambar 8. Cadangan Lukisan Kajian adabtasi pendekatan Chiaroscuro dan Tenebrisme

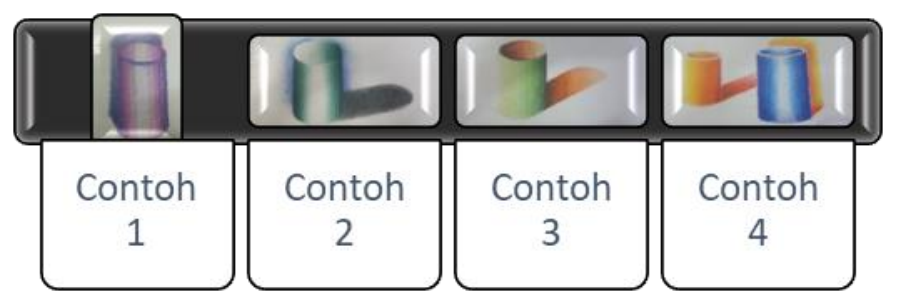

Gambar 9. Contoh pendekatan seni teknik warna panas, warna asal dan warna sejuk yang dicadangkan pengkajian dalam amalan studio gaya 'A+AGPD' 


\section{Catatan kaki dan ungkapan terima kasih}

Catatan kaki. Model ini direka untuk membantu siswazah seni reka, dalam masyarakat global bagi mengaplikasikan amalan studio praktis lukisan kajian gaya . Model ini akan dikembangkan, dipanggil Hybrid Model A + AGPD yang merupakan gabungan 'Art' + 'Architecture Graphic Presentation Drawing' dengan lukisan kajian yang dihasilkan. Penyelidik yang meneroka analisis mengkaji karya 'praktik studio' yang dihasilkan oleh SME pakar yang membimbing teori kritikal Edmund Burke Feldman untuk mensintesis pendekatan sistematik baru menghasilkan lukisan kajian 3D secara manual. Kajian ini bertujuan untuk menggabungkan lukisan lukisan gaya artistik dalam objek lukisan garis ilustrasi tiga dimensi secara manual dengan mencampurkan dua pengetahuan kemahiran lukisan kajian.

Ungkapan terima kasih. Kajian ini membantu dalam pengembangan kemahiran mahasiswa bidang rekaan mengaplikasikan kemahiran amalan studio praktis ilustrasi lukisan kajian gaya habrid seni dan seni bina. Terima kasih kepada pakar rujuk dalam kajian ini juga EMPAT(4) Subject Matter Expert (SME) dalam kajian ini. Terima kasih kepada pihak Universitas Indraprasta terutama Bapak Agung yang sudi menjemput saya sebagai Panel, Pihak Jabatan Pengajian Politeknik dan Kolej Komuniti terutama Pengurusan Politeknik Merlimau,Melaka yang memberi kebenaran kajian ini dilaksanakan dan sesi perkongsian ilmu dibuat kajian. Pendekatan baru ini akan menyumbang kepada kurikulum dan pedagogi dalam amalan studio praktik bidang seni reka yang boleh dipelajari dengan proses yang sistematik.

\section{Referensi}

[1] M. Li, Z. Lin, R. Měch, E. Yumer, and D. Ramanan, "Photo-sketching: Inferring contour drawings from images," 2019, doi: 10.1109/WACV.2019.00154.

[2] S. Mehrpour, T. D. Latoza, and R. K. Kindi, "Active Documentation: Helping Developers Follow Design Decisions," Proc. IEEE Symp. Vis. Lang. Human-Centric Comput. VL/HCC, vol. 2019Octob, pp. 87-96, 2019, doi: 10.1109/VLHCC.2019.8818816.

[3] N. Mayo, "Drawing into Practice," J. Vis. Art Pract., vol. 11, no. 1, pp. 75-81, 2012, doi: 10.1386/jvap.11.1.75.

[4] J.-W. Guo, X.-C. Cao, L. Xie, J.-J. Jin, and C.-D. Wang, "Development of Engineering Drawing Ability for Emerging Engineering Education,” IOP Conf. Ser. Mater. Sci. Eng., vol. 242, p. 012070, Sep. 2017, doi: 10.1088/1757-899X/242/1/012070.

[5] L. R. Masduki and E. Kurniasih, "Pengembangan Model Permainan Tradisional Sunda Manda Dalam Meningkatkan Multiple Intelegensi Siswa Dan Mahasiswa," JIPMat, vol. 2, no. 2, 2017, doi: 10.26877/jipmat.v2i2.1980.

[6] A. Garde, "Globalisasi Media Dan Penyerapan Budaya Asing, Analisis Pada Pengaruh Budaya Populerkorea Di Kalangan Remaja Kota Banda Aceh,” J. Ilmu Komun., vol. 3, no. 1, pp. 54-70, 2015.

[7] M. S. Nordin and M. S. Saud, "Kemahiran Visualisasi: Kemahiran Kognitif Tahap Tinggi Dalam Pendidikan Teknik Dan Vokasional.” 2006.

[8] M. S. N. \& D. A. Razak, "Tahap Kemahiran Visualisasi Dan Gaya Pembelajaran Pelajar-Pelajar Daerah Johor Bahru Dalam Mata Pelajaran Lukisan Kejuruteraan," 2010.

[9] M. S. S. \& K. S. Mohd Safarin Nordin, "Kesan Penggunaan Pemodelan Bongkah 3-dimensi dalam Pengajaran ke Atas Kemahiran Visualisasi Pelajar Aliran Teknikal Sekolah Menengah Teknik," Semin. Penyelid. Pendidik. Pasca Ijazah, UTM, pp. 93-105, 2008.

[10] M. Brooks, "Drawing to Learn," Science (80-. )., vol. 340, no. May, p. 903, 2003.

[11] P. Lyon, "Manual Drawing in Clinical Communication:Understanding The Role of Clinical MarkMaking," 4th Int. Vis. Methods Conf., vol. 5, no. 1, 2015. 
[12] S. M. Mohsenian, "A New Approach to the Role and Effects of Modern Art on Graphics," Int. J. Sci. Res., vol. 7, no. 1, pp. 262-266, 2016.

[13] Elun Loros, "Pendekatan Medium Hibrid Dalam Karya," Universiti Malaysia Sarawak, 2006.

[14] B. S. D. dan M. . Rahim, "Kajian Lukisan Still Life Jelekong," J. ATRAT V6, vol. 01, no. V6, pp. 25-30, 2018

[15] M. Mohammad, M. N. Ibrahim, M. R. M. Nasir, K. M. Jiddin, and M. F. Ahmad, "Art via Architecture 'Lukisan Kajian' Style in Hybrid Model 'A+AGPD': Observation 'Garisan stroke line' (gSLine)," Procedia - Soc. Behav. Sci., vol. 195, pp. 473-479, Jul. 2015, doi: 10.1016/j.sbspro.2015.06.490.

[16] H. Haron and D. Mohamed, "Pendekatan Pengoptimuman Dalam Penghasilan Objek Tiga Dimensi Daripada Lukisan Garisan Dua Dimensi," J. Teknol. 34(C)Jun 2001, vol. 34, no. C, pp. 53-62, 2001.

[17] V. Ostromoukhov and R. D. Hersch, "Artistic Screening," in Proceedings of the 22nd annual conference on Computer graphics and interactive techniques - SIGGRAPH '95, 1995, pp. 219-228, doi: $10.1145 / 218380.218445$.

[18] Ocvirk et al., Art Fundamentals Theory And Practice, Twelfth Ed. Mc Grow- Hill Companies,Inc.,1221 Avenue of The americas,New York,NY 10020, 2013.

[19] F. D.K.Ching, Architectural Graphics. Canada: John Wiley \& Sons,Inc, 2009.

[20] M. Szubielska, E. Niestorowicz, and B. Marek, "Drawing without eyesight. Evidence from congenitally blind learners," Rocz. Psychol., vol. 19, no. 4, pp. 681-700, 2016, doi: 10.18290/rpsych.2016.19.4-2en.

[21] D. Roşca-Ceban, "Fine Arts: 3. Contribution of the University Teaching Staff to the Development of Creative Imagination of the Fine Arts Profile Students," Rev. Artist. Educ., vol. 16, no. 1, pp. 182-189, 2018, doi: 10.2478/rae-2018-0019. 